\title{
INFLUENCE OF INTERMITTENT CYCLIC LOADING ON REINFORCED CONCRETE RESISTANCE MODEL
}

\author{
Scientiffic paper / Znanstveni rad \\ Vasyl Karpiuk \\ (Received: 24 July 2017; accepted: 20 December 2017) \\ Odesa State Academy of Building and Architecture,Department of Reinforced Concrete and Stone Structures, \\ $S c D$ \\ Anatoliy Kostiuk \\ Odesa State Academy of Building and Architecture,Department of Building Structures, PhD \\ Oksana Maistrenko \\ Odesa State Academy of Building and Architecture,Department of Reinforced Concrete and Stone Structures, \\ PhD

\section{Yulia Somina} \\ Odesa State Academy of Building and Architecture,Department of Reinforced Concrete and Stone Structures, \\ Assistant \\ Corresponding author: syomina3091@ukr.net
}

\begin{abstract}
This article describes the study of reinforced concrete span bending structures under conditions of highlevel cyclic loading. Previous studies on the development of physical models of bending reinforced concrete element fatigue resistance, cyclic effect of lateral forces, and methods of calculation, are important and appropriate owing to certain features and the essential specificity of the mentioned loading type. These primarily include the nonlinearity of deformation, damage accumulation in the form of fatigue micro- and macro-cracks, and exhausting destruction of construction materials. In this paper, key expressions determining the endurance limits of concrete, longitudinal reinforcement, and anchoring longitudinal reinforcement, which contribute to endurance throughout the entire construction, are considered. Establishing a link between stresses in the elements and deformations in the element under conditions of cyclic loading action is of equal importance because of the presence of cyclic stressinduced creep deformation.
\end{abstract}

Keywords: endurance; cyclic loading; exhausting destruction; cyclic stress-induced creeps; reinforced concrete

\section{UTJECAJ NAIZMJENIČNOG CIKLIČKOG OPTEREĆENJA NA OTPORNOST ARMIRANOBETONSKIH ELEMENATA OPTEREĆENIH NA SAVIJANJE}

Sažetak: Ovaj članak posvećen je proučavanju ponašanja rasponskih konstrukcija od armiranog betona pri djelovanju visokih razina cikličnog opterećenja. Autori su utvrdili da su studije o razvoju fizikalnih modela otpornosti na zamor savojnih armiranobetonskih elemenata, utjecaja cikličkog djelovanja na poprečne sile i pripadajućih metoda proračuna, osobito važni i prikladni zbog karakteristika i bitne specifičnosti spomenutog tipa opterećenja. To prvenstveno uključuje nelinearnost deformacije, akumulaciju oštećenja u obliku mikro i makropukotina pri zamoru, izraženi slom u materijalu i tako dalje. U radu su prikazane jednadžbe za određivanje granica izdržljivosti betona, uzdužne armature i sidrenja uzdužne armature, koje osiguravanju izdržljivost za cijelu konstrukciju. Jednako je važno, kao što je navedeno u ovom članku, uspostaviti vezu između naprezanja i deformacija u elementu u uvjetima djelovanja cikličkog opterećenja, jer postoji mogućnost nastanka deformacija zbog puzanja pri cikličkim naprezanjima.

Keywords: izdržljivost; cikličko opterećenje; izraženi slom; puzanje zbog cikličnog opterećenja; armirani beton

Karpiuk, V, Kostiuk, A, Maistrenko, O, Somina, Y 


\section{INTRODUCTION}

This paper considers the peculiarities of changing the stress-strain state of structures depending on the size of the distance from the support of the element to the location of concentrated force action. This, in turn, affects the scheme of destruction and the distribution of existing forces in the force flux of concrete and the reinforcement of an element. Additionally, the physical models are cited and expressions are calculated in order to determine the endurance limit (objective fatigue strength) of composite materials in structures consider the real stress-strain state of areas near the supports of these members under conditions of repeated loading depending on the varying distance from an element's support to the location of a concentrated force action.

According to the existing design rules [1], the calculation of the endurance of reinforced concrete structures is carried out under the assumption of elastic concrete work. This approach to the calculations is in contradiction to the real nature of inelastic work for reinforced concrete elements, and does not reflect the fracturing behaviors of reinforced concrete structures in the area of transverse force actions during cyclic loading.

Accordingly, the novelty of our study is that the definition of a structural material's endurance limit (objective strength) by determining the real physical and geometric data of the considered sections, and appropriate relationships of the stress and deformations distributions under conditions of cyclic fatigue, while taking into account the availability of cyclic strain-induced creep deformations, accumulation of residual strains, and residual stresses.

Theoretical studies on the development of fatigue resistance physical models of bending reinforced concrete elements, the cyclic effects of the transverse forces and the methods of calculation based on them are practically missing. Therefore, in this study, the development of physical models of fatigue resistance and the fracture of areas near the supports of the reinforced concrete bending elements, which would accurately reflect their real work by considering real concrete and steel deformation elements at different distances from the support of the element to the location of the concentrated force action. At the same time, appropriate methods of calculation have only just emerged.

In this context, the main contribution of this study is that it accumulates good preconditions for new engineering methods of calculating the strength of areas near the supports of reinforced concrete structures, with consideration to the change in their stress-strain state and the changing strength properties of the concrete, and reinforcements and their catenation. Then, this can be applied to the entire range of material strength characteristics, which range from low-cycle repeated loading to frequent cyclical loading.

In Section 2, a literature review that was carried out within the framework of the investigated subject is presented. Section 3 is concerned with the description of the work of reinforced concrete members at zero distance from the an element's support to the location of the concentrated force action, which emphasizes the fact that the work of a reinforced concrete member under such conditions is similar to the work of a concrete member subjected to local compression. Section 4 clarifies the structural resistance models with small, medium, and large distances from an element's support to the location of the concentrated force action. It was observed that there were some features of the member's stress-strain state, depending on the change of this factor. Namely, the feature of the reinforced concrete elements with a small distance from the support of the element to the location of concentrated force action is the formation of local stress zones associated with the loading points of concentrated external forces, within which there is exhausting destruction. The exhausting destruction of areas near the supports of elements with a large distance from the element's support to the location of concentrated force action, occurs with the formation of a critical inclined crack, whose position is associated not only with the loading points of external forces and support reactions, but also with the internal force factors arising in areas near the supports (moments and transverse forces). In elements with middle distance from the element's support to the location of concentrated force action, the nature of formation and development of cracks and the exhausting destruction in this area, during the specified loading, exert an effect as internal force factors and local stress concentration in the relevant areas near the points of the concentrated external forces. In Section 5, conclusions are drawn and the reviewed information is summarized and discussed.

Karpiuk, V, Kostiuk, A, Maistrenko, O, Somina, Y 


\section{LITERATURE REVIEW}

With consideration to the relevance of the chosen research topic and the need to update the research data within the framework of these studies, many scientists have focused on this issue. Reports of experiments found by literature review [2-12] indicate that repeated cyclic loading has a unique effect on the operating character of reinforced concrete structures. When exposed to the mentioned type of loading deflection valuesand the width of opening the normal and inclined cracks of elements increases, on average, by $15 \ldots 20 \%$, deformation values of the reinforcement and concrete also increases by $10 . . .15 \%$, and the bearing capacity of reinforced concrete structures decreases by approximately $20 \%$. Additionally, various researchers [3-7] have found that, at operating load levels, the conventional stabilization of strains and stresses in the members occur at 5-7 cycles. However, if the stress levels exceed the operational levels, such predictions cannot be made.

Despite the rather large volume of research carried out and the establishment of predictions for the performance of reinforced concrete structures under the influence of cyclic repeated loading, researchers have not yet reached an agreement on how to account for this influence in practical engineering calculations to obtain the strength of normal and inclined member. Most researchers $[3,5]$ continue to consider the cyclic component of the load at the expense of the coefficient of working conditions, which does not reflect the real mechanics of work and the destruction of reinforced concrete structures by the actions of the specified loading type.

\section{REINFORCED CONCRETE MEMBER RESISTANCE MODEL WITH A ZERO DISTANCE FROM ELEMENT SUPPORT TO LOCATION OF CONCENTRATED FORCE ACTION}

Mirsayapov [2], Zalesov and Klimov [13], have identified the main forms of the exhausting destruction of reinforced concrete structures, by depending on the distance from element's support to the location of concentrated force action, as follows: $c_{0} / h_{0}$ elements with a zero $\left(c_{0} / h_{0}=0\right)$, with low $\left(c_{0} / h_{0} \leq 1,2\right)$, with middle $\left(1,2 c_{0} / h_{0} \leq 2\right)$, and with a large $\left(c_{0} / h_{0}>2\right)$ distance from the element to the location of concentrated force action. Mirsayapov [2] used thermal imaging and showed that in elements with $c_{0} / h_{0} \leq 1,2$ there are local stresses that strake between the points of application of the concentrated force and the element's reference reaction, within which there is exhausting destruction. With the further decrease of the distance from the support of the element to the location of concentrated force action, the limiting case occurs where $c_{0} / h_{0}=0$ and $M_{\max }=Q_{\max }=0$. In other words, there is a local compression, which can also be put into the overall protection system of reinforced concrete elements to the action of transverse forces.

Based on the research carried out by Mirsayapov [2], Zalesov [14] and Kholmyanskiy [15], the physical fatigue resistance model of concrete in this exercise can be presented as described below. The element directional tracking compressive force flow, limited by the sizes of load areas, is formed by the local compression of the concrete. Inside this flux, the stress state is dissimilar, since the load is applied again to the flat element under load areas with limited width friction forces appearing between these areas and the concrete surface. Because of this, concrete body compacted volumes are produced in the form of a wedge (Figure 1a) with sides inclined to transferring the load area with an angle equal to the angle $\varphi$ of the concrete internal displacement (Figure 1b). Inside the stress wedge state, "compression-compression" is formed $\left(\sigma_{1 c}^{\max }(t), \sigma_{2 c}^{\max }(t)\right)$. Moving the wedge, as a solid, and its "jamming" in the surrounding concrete, causes the appearance of resistance and, consequently, the appearance of splitting (tensile) stress $\sigma_{2 c t}^{\max }(t)$ between the peaks of the impaction wedges and along the sides of the wedge. Thereby, the condition of pure shear is realized and the tangential stress $\tau_{12}^{\max }(t)$ appears. As a result of the pressure from these impaction sides, as a solid, on the surrounding concrete, the compressive stress $\sigma_{1 c}^{\max }(t)$ also appears (Figure 1c). Therefore, in the middle zone between the peaks of the impaction wedges in the sealing elements with dimensions $h \leq 1,5 L$ and $l_{\text {loc }} / h>0,2$, in accordance to Sokolov [16], the compression core with a width of $l_{e f,}$ which is less than the width of the loading platform $l_{\text {loc., }}$ is formed. 
Consequently, the criterion of exhausting the concrete's destruction with local repeated compression can be represented as $\sigma_{1 c}^{\max }(t)>f_{c d, \text { rep }}(t)$, where $f_{c d, \text {,rep }}(t)$ is the objective (residual) strength of the concrete in the compressive stress force flow during the cyclic loading at time $t ; \sigma_{1 c}^{\max }(t)$ is the maximum compressive stress of the cycle from the external load at time $t$.

a)

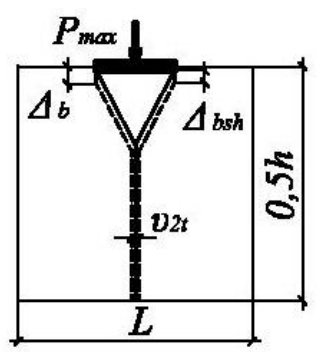

b)

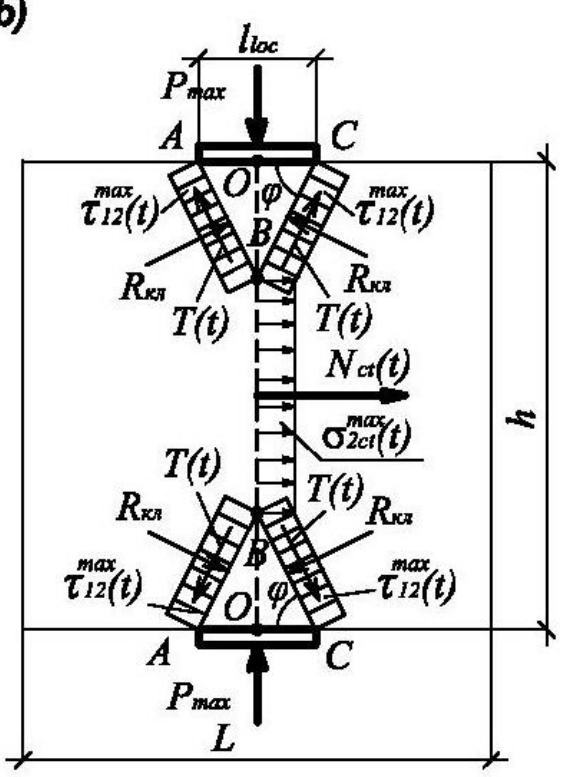

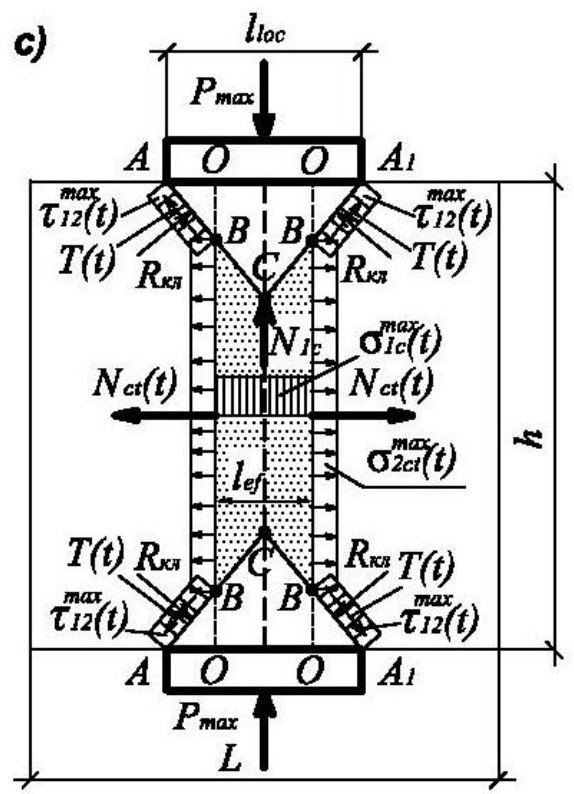

Figure 1 (a) Model of concrete deformation under local compression re-loading, (b) stress distributions in compressed elements with zero distance from the support of element to the location of concentrated force action during cyclic loading at $I_{l o c} / h<0,2$, and(c) at $I_{l o c} / h>0,2$ according to [2]

where $P_{\text {max: }}$ : maximum loading of cycle.

$\Delta_{b}$ : displacement of sealing wedges in vertical direction.

$\Delta_{b s h}$ : shear of concrete along the edges of sealing wedges.

$v_{2 t}:$ transverse displacement in the central zone.

$h$ : height of element cross-section. L: length of element.

$l_{l o c}$ : width of load area.

$\tau_{12}^{\max }(t)$ : maximum tangential stress.

$T(t)$ : maximum tangent force in concrete of element surrounding sealing wedge.

$R_{\kappa r}:$ force in concrete of element surrounding sealing wedge.

$N_{c t}(t)$ : concrete tensile force in the central zone of an element.

$\sigma_{2 c t}^{\max }(t)$ : maximum tensile stress.

$\sigma_{1 c}^{\max }(t)$ : maximum compressive stress.

$N_{1 c}:$ maximum compressed force in compression core.

$\varphi$ : angle of internal concrete displacement before the appearance of rupture crack.

$l_{\text {ef. }}$ width of compression core.

The fatigue resistance model of a reinforced concrete element serves as the basis of fatigue resistance for a concrete element with local compression. Their geometric parameters and construction principles are the same. The distribution of stresses in the concrete of a reinforced concrete element with the first load and during

Karpiuk, V, Kostiuk, A, Maistrenko, O, Somina, Y 
cyclic loading, as well as the concrete deformation schemes, are considered the same as those in the concrete elements (Figure 1, $a, b, c$ ). The vertical displacement of the sealing wedges in the concrete elements is resisted by the surrounding concrete. The impact of horizontal and vertical reinforcement in the above mentioned equilibrium conditions for the $\mathrm{ABO}$ semi-wedge and for $\mathrm{OO}$ vertical section (Figure 3) is considered as the forces $N_{s c}^{\max }(t) ; Q_{s}^{\max }(t) ; N_{s}^{\max }(t)$ in the reinforcement. For the evaluation of the objective (residual) bearing capacity of the reinforced concrete element at local compression under cyclic loading, the following equilibrium equations are in effect:

- equilibrium condition of vertical forces for the $A B C$ sealing wedge in the reinforced concrete element:

$\sum Y=0 ; \quad 2 R_{\kappa /} \cos \varphi+2 T^{\max }(t) \sin \varphi+N_{1 c}^{\max }+N_{s c}^{\max }(t)+Q_{s}^{\max }(t)-N_{t}^{\max }(t, \tau)=0$

where $R_{\kappa л}$ : force in concrete of element surrounding sealing wedge.

$\varphi$ : angle of internal concrete displacement before the appearance of rupture crack $\varphi=\operatorname{arctg}\left[0,48\left(l_{l o c} / h\right)^{2 / 3}\right]$.

$T^{\max }(t)$ : maximum tangent force in concrete of element surrounding sealing wedge.

$N_{1 c}^{\max }$ : maximum compressed force in compression core.

$N_{s c}^{\max }(t)$ : maximum forces in top (compressed) longitudinal reinforcement.

$Q_{s}^{\max }(t)$ : maximum dowel force.

$N_{t}^{\max }(t, \tau)$ : objective (residual) bearing capacity of reinforced concrete element under cyclic load at time $t$.

- equilibrium condition of horizontal forces for the $\mathrm{ABO}$ half-sealing wedge in the reinforced concrete element:

$\sum X=0 ; \quad R_{\kappa л} \sin \varphi-T^{\max }(t) \cos \varphi-N_{b c, \kappa л}=0 ;$

where $R_{\kappa л}, \varphi, T^{\max }(t)$ are according to (1).

$N_{b c, \kappa л}$ : tensile force in concrete in a sealing wedges element.

- equilibrium condition of horizontal forces for the $\mathrm{OO}$ vertical section in the reinforced concrete element (for upper half of the element):

$\sum X=0 ; \quad 0,5 N_{t}^{\max }(t, \tau) \cos \varphi-N_{b c, \kappa л}=0$

where $N_{t}^{\max }(t, \tau)$ and $\varphi$ are according to (1).

$N_{b c, \kappa л}$ is according to (2).

Hence, the analytical expression of the objective strength of reinforced concrete under the compressive force flux during cyclic loading at time $t$ is obtained as follows:

$$
\begin{aligned}
& f_{c d, \text { rep }}(t)=\frac{h_{t} \operatorname{ctg} \varphi}{l_{l o c} \sqrt{\pi l(t)} \cdot Y(l)} \times\left\{k_{s c f}(t)+\sum_{i=1}^{h} \frac{\sigma_{s i}^{\max }(t) A_{s}}{b \cdot \sqrt{\pi \cdot l}(t)}\left(\begin{array}{l}
\sqrt{\frac{l(t)+(i-0,5) \cdot s}{l(t)-(i-0,5) s}}+ \\
+\sqrt{\frac{l(t)-(i-0,5) \cdot s}{l(t)-(i+0,5) \cdot s}}
\end{array}\right\} \times\right. \\
& \times\left\langle A-\left\{\mathrm{G}_{\mathrm{c}} L_{\varepsilon} B+\frac{6 E_{s} I_{s} L_{\varepsilon} \cdot n}{b \cdot\left(d_{s} \cdot \sqrt[4]{\frac{E_{s}}{E_{c}}} \cdot\left(1,4+1,25 \sqrt[4]{\frac{a_{s}}{d_{s}}}\right)\right)^{3}}+C\right\} \times\left\{\frac{1}{E_{c}}+C_{e} \prod_{k=1}^{k=n} K_{k} a \cdot \psi_{v}+\int_{t_{o}}^{t} \frac{\partial}{\partial \tau}\left[\frac{1}{E_{c}(\tau)}+C(t, \tau)\right] d t\right\}\right)^{-1}
\end{aligned}
$$


where $h_{t}$ : height of tensile zone, $h_{t}=H-l_{l o c} \cos \varphi \sin \varphi . l(t)$ : length of fatigue crack.

$Y(l)$ : dimensionless factor.

$k_{s c f}$ : critical stress intensity factor of reinforcement by repeated loads at time $t$.

$\sigma_{s i}^{\max }:$ stress in longitudinal reinforcement.

$A_{s}$ : cross-sectional area of longitudinal reinforcement.

$b$ : cross-sectional width.

$i$ : quantity of transverse reinforcement rods crossing the half-length of the fracture.

$s$ : distance between the bars of transverse reinforcement.

$L_{\varepsilon}:$ coefficient characterizing the force flux direction, $L_{\varepsilon}=\frac{1}{\pi}\left(\left(2 \theta_{\kappa}-\pi\right) \cdot \operatorname{tg} \theta_{\kappa}-\left(2 \theta_{H}-\pi\right) \cdot \operatorname{tg} \theta_{H}\right)$ $\theta_{\mathrm{H}}=\operatorname{arctg} \sin \varphi \cos \varphi, \theta_{\kappa}=\operatorname{arctg} \frac{h}{l_{l o c}}$.

$G_{c}$ : shear modulus of concrete.

$E_{s}$ : longitudinal reinforcement modulus of elasticity.

$I_{s}$ : cross section moment of inertia.

$n$ : quantity of transverse rods in area between the element's support and the location of center-point loading. $d_{s}$ : diameter of longitudinal reinforcement.

$E_{c}$ : concrete modulus of elasticity.

as: protective layer of longitudinal reinforcement of concrete.

$C$ : measure of cyclic creep of concrete.

$C_{e}$ : limit measure of sample creep.

$K_{k}$ : correction factor for determining the limit creep measure.

$a$ : function that takes into account the strength properties of concrete and its age.

$\psi_{v}$ : ratio that considers the influence of loading speed.

$A=1$ and $B=1 / \sin ^{2} \varphi$ - for concrete elements with dimensions $H \leq 1,5 L$, $I_{10 c} / H<0,2$; and for concrete elements with $H>1,5 L ; A=\cos ^{2} \varphi$ and $B=\operatorname{ctg}^{2} \varphi$ - for concrete elements with dimensions $H \leq 1,5 L, l_{10 c} / H$ $>0,2$.

$\varphi$ : angle of internal concrete displacement before the appearance of rupture crack $\varphi=\operatorname{arctg}\left[0,48\left(l_{l o c} / h\right)^{2 / 3}\right]$.

\section{REINFORCED CONCRETE ELEMENT RESISTANCE MODELS WITH SMALL, MEDIUM, AND LARGE DISTANCES FROM ELEMENT SUPPORT TO THE LOCATION OF CONCENTRATED FORCE ACTION}

Mirsayapov [2] and various researchers [10,11] have shown that with $c_{0} / h_{0}>2$, the exhausting destruction of areas near the supports of bending elements occurs by forming a critical inclined crack, whose position is associated not only with the points of application of the external force and support reaction, but also with the internal force factors arising in the area between the support of an element and the location of concentrated force action (in moments and with transverse forces). If $1,2<c_{0} / h_{0} \leq 2$, the nature of the formation and the development of cracks, as well as the exhausting destruction in this area during the specified loading, has an impact on the internal force factors and the local stress concentration in the relevant areas near the points of concentrated external forces.

Karpiuk, V, Kostiuk, A, Maistrenko, O, Somina, Y 
The peculiarity of "long" bending reinforced concrete elements with small distances from the element's support to the location of the concentrated force action $\left(a_{0}<1,2 h_{0}\right)$ is the formation of the local stress bands associated with the point of application of concentrated external forces, within which the exhausting destruction occurs. This feature of ordinary reinforced concrete elements with small distances from the element's support to the location of concentrated force action unites them with "short" elements, where $h / L<1 / 2$ (for example, it is the column console). In both cases, this feature manifests itself at small values of the relative distance between the forces acting on the element.

Sokolov [16] and Baranova [17] believe that for the practical calculations of "short" elements the easiest solution of the problem is the creation of a computational model in the form of the skeletonized bar system (SBS), which consists of sloping compressed bands and stretched lower and compressed upper reinforcing belts that are closed in the application areas of concentrated forces and support reactions (Figure 2).

The principle of building a computational model lies in determining the compressive stresses in the inclined force flux, and the tensile stresses in the horizontal strip, whose intersection forms a system that can be called a skeletonized-bar model of short elements. The main parameters defining the physical characteristics of the calculated inclined strips are the dimensions of load $l_{\text {sup }}^{\text {top }}$ and supporting areas $l_{l o c}^{\text {bot }}$, under which, the flows of compressive stresses are formed (Figures 3-5). The smaller the sizes of these areas are, the higher is the density of the trajectories. Consequently, the supporting and loading areas form a slope and its width from both above and below. The inclination angle of the main compressive stress strip is close to the inclining angle of the line connecting the centers of the application of the reference reaction and the external concentrated force.
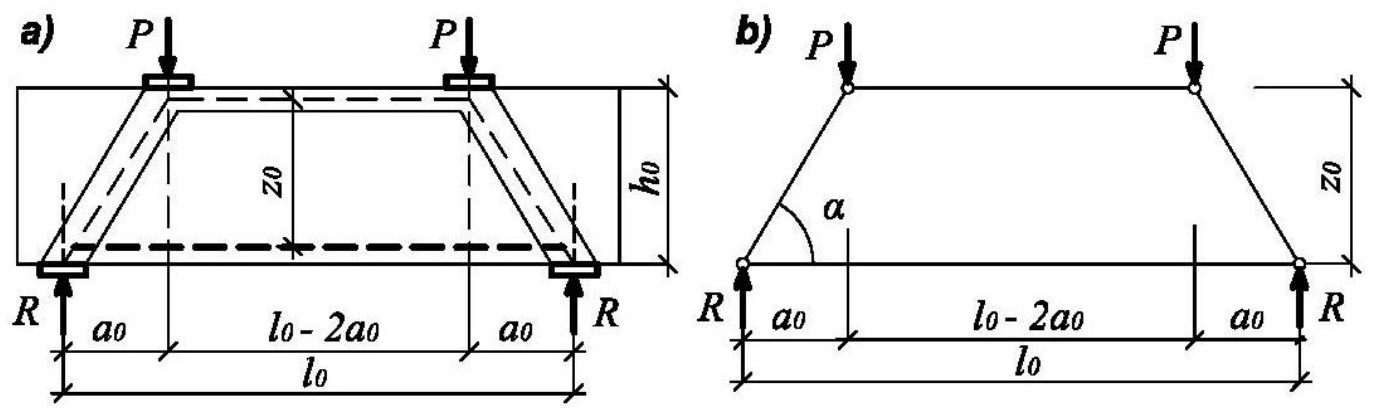

Figure 2 Generation of force strip in ordinary (long) elements with small distance from element's support to location of concentrated force action: (a) at reloading; (b) its skeletonized-bar analogue

where $a_{0}=c_{0}$ : distance from the element's support to the location of center-point loading.

$h_{0}=d$ : distance from the element's compressed edge to the gravity center of tensile longitudinal reinforcement.

$P$ : concentrated loading.

$R$ : supporting reaction.

$l_{0}$ : distance between supports.

zo: distance between skeletonized bars.

$\alpha$ : inclination angle of compressed strip.

Obviously, when modeling the work of the area close to the concrete element supports, for small distances from the element's support to the location of the concentrated force action with a skeletonized bar analogue, it can be assumed that its fatigue strength is determined by the endurance of each SBS element, sloping compressed strips, and strength of stretched reinforcement. The fatigue destruction of the stretched zone element is the result of the fatigue rupture of the longitudinal reinforcement in the intersection of the inclined crack, or a breach of the reinforcement anchoring at the inclined crack. Therefore, the emerging stresses need to be limited to the values of the objective (residual) strength during the cyclic loading (endurance) of the concrete, while the reinforcements and the catenation between them, are required to adhere to the conditions of endurance, in order to ensure the durability of such reinforced concrete elements, as follows:

$\sigma_{1 c}^{\max }(t) \leq f_{c d, \text { rep }}(t), \sigma_{s, b}^{\max }(t) \leq f_{y d q, \text { rep }}(t), \sigma_{s}^{\max }(t) \leq f_{y d, \text { an }}(t)$ 
where $\sigma_{1 c}^{\max }(t)$ : maximum compressive stress.

$f_{c d, \text { rep }}(t)$ : objective (residual) strength of concrete in compressive stress force flux during cyclic loading at time $t$. $\sigma_{s, b}^{\max }(t)$ : the current tensile stress in the most loaded fibers of longitudinal reinforcement at the intersection with the inclined crack.

$\sigma_{s}^{\max }(t)$ : current (maximum) axial tensile stress in the longitudinal reinforcement at the intersection with the inclined crack.

$f_{y d q, \text { rep }}(t)$ : limit of endurance of longitudinal reinforcement for tension.

$f_{y d, a n}(t)$ : limit of endurance of longitudinal reinforcement anchoring.

Experimental studies $[2,16,17]$ have shown that the stress-strain state inside the old compressive force strip is the same as the planar stressed elements for the actions of local loading. Therefore, to estimate the fatigue strength of an inclined compressed strip, a model of exhausting destruction in compression and the objective (residual) strength of the concrete and reinforced concrete with the cyclic loading equation can be applied. At the same time, if axis "1" (Figure 3 ) is directed along the longitudinal axis of the inclined compression force flux, and axis "2" is in the orthogonal direction, and accept the same designations as the elements with zero distances from the element's support to the location of the concentrated force action, then, the stressed state within an inclined compressed force flux is represented as shown in Figure 3.

As in local compression, the development of cyclic stress-induced creeps $\mathcal{E}_{1 c \text {, pl }}$ in compressed concrete towards stress $\sigma_{l c}^{\max }\left(t_{0}\right)$, occur under free conditions; thereby, nothing prevents their development; therefore it can be assumed that $\sigma_{1 c}^{\text {add }}(t)=0 ; \sigma_{s}^{a d d}(t) \approx 0 ; \sigma_{1 c}^{\max }(t)=\sigma_{1 c}^{\max }\left(t_{0}\right) ; \sigma_{s}^{\max }(t) \approx \sigma_{s}^{\max }\left(t_{0}\right)$, $\sigma_{1 c}^{\max }\left(t_{0}\right)$ and $\sigma_{s}^{\max }\left(t_{0}\right)$ are quite simply determined at the first load from equilibrium conditions based on the model of fatigue resistance.

Due to the fact that the stress-strain state within the inclined compressed band, the nature of its exhausting destruction, and the nature of the exhausting destruction of the flat-stressed members for local stress action expressions to determine the objective fatigue strength (endurance limit) of the compressed inclined stripes on time $t$ on the analogy of (4), take the form (6). 


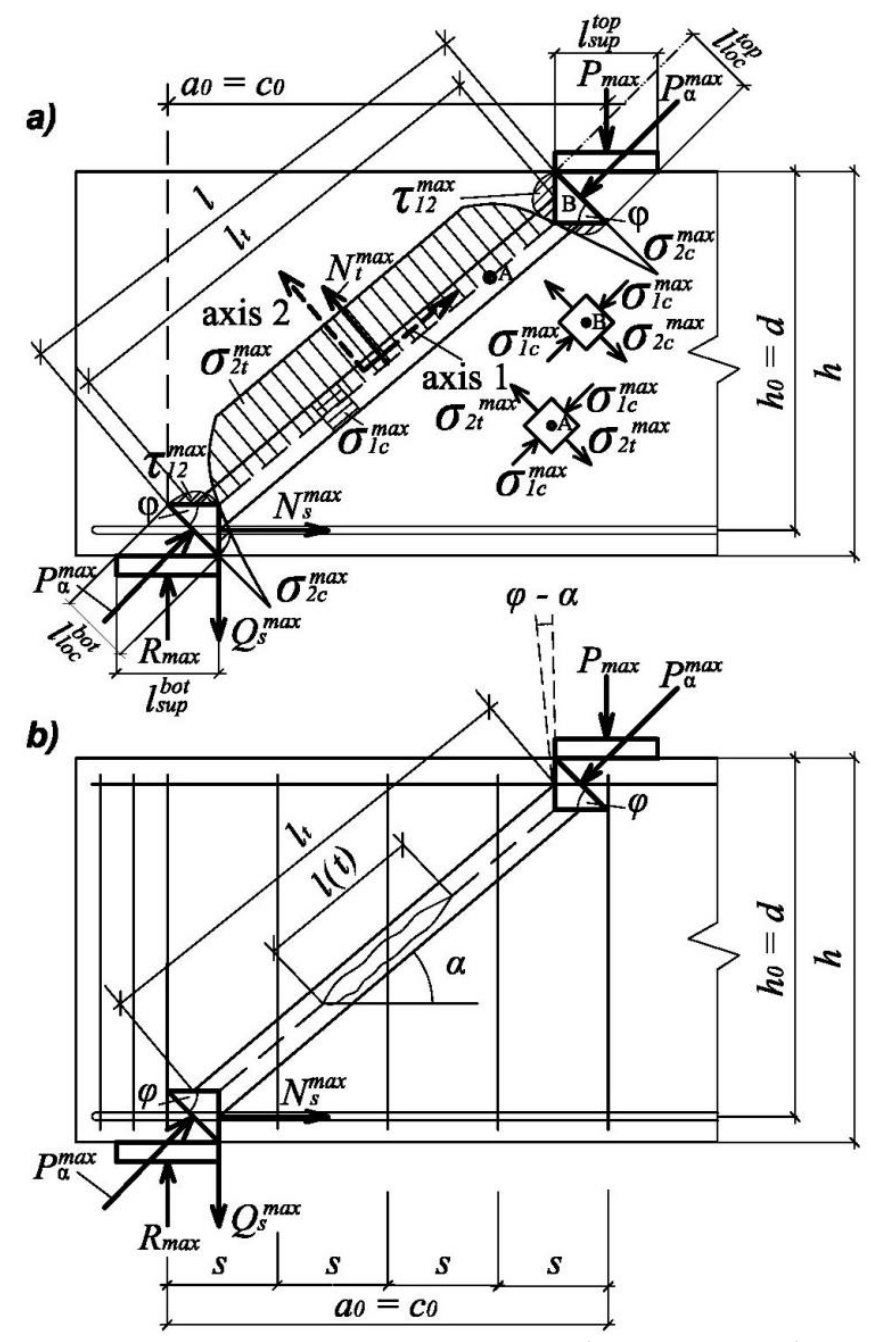

Figure 3 (a) Physical model and (b) calculation scheme of bending reinforced concrete element resistance, with small distance from element support to location of concentrated force actionto joint action of transverse force and bending moment

where $P_{\max }, h, \tau_{12}^{\max }(t), \varphi, \sigma_{1 c}^{\max }(t)$ are according to Figure 1.

$h_{0}=d ; a_{0}=c_{0}$ are according to Figure 2.

$N_{s}^{\max }(t)$ : maximum forces in bottom (tensile) longitudinal reinforcement.

$N_{t}^{\max }(t)$ : maximum tensile forces in compressed strip.

$l_{\text {sup }}^{\text {top }}, l_{\text {sup }}^{\text {bot }}$ : width of upper and bottom supporting areas.

$l_{l o c}^{\text {top }}, l_{l o c}^{b o t}:$ width of upper and bottom areas.

$P_{\alpha}^{\max }$ : objective (residual) strength of inclined compressed strip.

$l_{t}$ : length of inclined compressed strip.

$l(t)$ : length of fatigue crack

$l$ : general length of inclined compressed strip considering the dimensions of sealing wedges.

$R_{\text {max }}$ : supporting reaction.

$s:$ distance between the bars of transverse reinforcement. 
$\sigma_{2 t}^{\max }(t)$ : maximum tensile stress in compressed strip.

$\sigma_{2 c}^{\max }(t)$ : maximum tensile stress in sealing wedge.

$Q_{s}^{\max }(t)$ : maximum dowel force.

$$
\begin{aligned}
& f_{c d, r e p}(t)=\frac{\left(k_{\text {scf }}(t)+K_{i s w}(t) \cos \alpha\right) \cdot l(t) \operatorname{ctg} \varphi}{l_{\text {sup }} \sin \alpha \sqrt{\pi l(t)} Y(l)} \times \\
& \times\left\langle A_{\mu n}-\left\{G_{c} L_{\varepsilon} B_{H n}+\frac{6 E_{s} I_{s} L_{\varepsilon} \cdot n \cdot \cos (\varphi-\alpha) \sin \alpha}{b\left(d_{s} \sqrt[4]{\frac{E_{s}}{E_{c}}}\left(1,4+1,25 \sqrt[4]{\frac{a_{s}}{d_{s}}}\right)\right)^{3} \sin \varphi}\right\} \times(6)\right. \\
& \left.\times\left\{\frac{1}{E_{c}}+C_{e} \prod_{k=1}^{k=n} K_{k} a \psi_{v}+\int_{t_{o}}^{t} \frac{\partial}{\partial \tau}\left[\frac{1}{E_{c}(\tau)}+C(t, \tau)\right] d t\right\}\right\rangle^{-1}
\end{aligned}
$$

where $l(t), Y(l), k_{s c f}, b, L_{\varepsilon}, G_{c}, E_{s}, I_{s}, n, d_{s}, E_{c}, a_{s}, C, C_{e}, K_{k}, a, \psi_{v}, \varphi$ are according to (4).

$K_{i s w}(t)$ : stress intensity factor characterizing the transverse reinforcement effect on the development of cracks in the inclined compressive strip and in elements without transverse reinforcement $K_{\text {isw }}=0 . A_{u n}=1$, $B_{u n}=1 / \sin ^{2} \varphi$ : coefficients for concrete elements with dimensions of loading area $I_{\text {sup }} / h<0,2 ; A_{\mu n}=\cos ^{2} \varphi$, $B_{H n}=\operatorname{ctg}^{2} \varphi-$ for concrete elements with dimensions of loading

area $I_{\text {sup }} / h \geq 0,2$. $l_{\text {sup: }}$ loading area.

$\alpha$ : inclination angle of compressed strip.

The multi-cycle fatigue of reinforcement is characterized by the formation and development of fatigue cracks. The origination of fatigue cracks is the result of the intensive plastic deformation of the reinforcing steel in the local volumes of stress concentration in the fixtures, which is the main source of the periodic reinforcement profile. After the exhausting plastic deformation in these local volumes, the cracks are formed, and one of them could turn into the main crack. With the further increase in the number of loading cycles, the increase of the main crack to critical size occurs (the opening width of the main inclined crack exceeds $1 \mathrm{~mm}$ ). In this respect, and with regard to the analytical description of the exhausting destruction processes and changes by repeated stress in the fatigue strength of steel reinforcement in the reinforced concrete member,the methods of fracture mechanics are applied. The limit of endurance (objective strength) of the longitudinal reinforcement at time $t$ at the location of its intersection with inclined crack, takes the following form:

$f_{s d, B}(t)=\sigma_{s c} \cdot k_{s c f}(t) / \sqrt{\left(Y(l) \cdot \sigma_{s c}\right)^{2} \cdot l(t)+k_{s c f}^{2}(t)}$

where $l(t), Y(l), k_{s c f}$ are according to (4).

$\sigma_{s c}=\sigma_{u} /\left\langle 1+\exp \left(-2 E_{s} \cdot \varepsilon_{p l}^{p e c} / \sigma_{s u}\right) \sqrt{1+3\left(\tau_{s i}^{\max } / \sigma_{s b i}^{\max }\right)^{2}}\right\rangle$

where $\sigma_{s b i}^{\max }, \tau_{s i}^{\max }$ are normal stresses in the most loaded (stretched) fibers and tangential stresses in the longitudinal reinforcement in the place of its intersection with an inclined crack, respectively.

$\sigma_{s u}:$ temporary resistance of steel rupture.

$\sigma_{u}:$ limit stress of steel rupture.

Karpiuk, V, Kostiuk, A, Maistrenko, O, Somina, Y 
$\varepsilon_{p l}^{p e c}:$ residual plastic resource of steel.

The process of the multi-cycle fatigue anchoring of fixtures is characterized by the formation and development of fatigue cracks in the contact zone between the reinforcement and concrete. If the stress level of reinforcement catenation with concrete $\tau_{g}$ is high, and these tensions are greater than the endurance limit of catenation, that is, if the condition of $\tau_{g} / \tau_{\text {rep }}>1$ is performed, then the emergence and development of internal fatigue cracks occurs in the contact zone between the reinforcement and concrete. As has been reported by Kholmyanskiy [15], Goto [18] and Karpenko [19], these cracks form cone-shaped volumes. The cracks mentioned above are primarily developed under the protrusions of reinforcement and penetrate the thickness of the concrete, which is smashed under these protrusions. Therefore, the objective fatigue strength of the concrete under these protrusions, and therefore the adhesion forces of the reinforcement protrusions with concrete, must be determined as a function of the cone-shaped crack $l(t)$, whose length continuously increases with the number of loading cycles. Therefore, the application of the analytical characteristics of the exhausting destruction process in the contact zone, changes in fatigue strength of the longitudinal reinforcement anchoring by repeated stress, and methods of fracture mechanics, is also advisable. Then, the endurance limit of (objective strength) of the longitudinal reinforcement anchoring at time $t$ is defined by:

$$
\begin{aligned}
& f_{y d \text { an }, \text { rep }}(t)=k_{\text {scf }}(t) \operatorname{ctg} \varphi\left(\frac{1,5 a}{\cos \varphi_{k}}-\frac{c_{r}}{\sin \varphi_{k}} \sin \varphi \cos \varphi\right) \times \\
& \times\left(d+2 c_{r}+\left(0,75 a-0,5 c_{r} \operatorname{ctg} \varphi_{k} \sin \varphi \cos \varphi\right)\right) \times \\
& \times\left(1,5\left(1+\sin \alpha_{r}\right)-\sqrt{\sin \alpha_{r}}\right) \cdot \frac{2 \tau_{g}\left(d+2 c_{r}\right)\left(L+L_{p l}\right)}{d^{2}} \times \\
& \times\left(\sqrt{\pi l(t, \tau)} \cdot Y(l) s_{r}\left(d+2 c_{r}\right) \sin 2 \varphi_{k} \sin \alpha_{r}\right)^{-1} \times \\
& \times\left(1-\frac{G_{c}\left(3 a \operatorname{tg} \varphi_{k}-2 c_{r} \sin \varphi \cos \varphi\right)}{c_{r} \cos \varphi \sin ^{2} \varphi} \cdot \frac{A_{s h}}{A_{c}}\left\{\begin{array}{l}
\frac{1}{E_{c}}+C_{e} \prod_{k=1}^{k=n} K_{k} a \psi_{v}+ \\
+\int_{t_{o}}^{t} \frac{\partial}{\partial \tau}\left[\frac{1}{E_{c}(\tau)}+C(t, \tau)\right] d t
\end{array}\right\}\right\rangle^{-1}
\end{aligned}
$$

where $Y(l), k_{s c f}, G_{c}, E_{c}, C, C_{e}, K_{k}, a, \psi_{v}, \varphi$ are according to (4).

$\tau_{g}$ : catenation stress level of reinforcement with concrete.

$d$ : rod diameter.

$c_{r}, s_{r}, \alpha_{r}:$ respectively, height, step and tilt angle of reinforcement protrusions.

a: protective layer of concrete.

$L, L_{p l}$ :length of fixing reinforcement in concrete and plastic areas of this fixing.

$\varphi_{k}$ : angle of wedge under reinforcement protrusions.

$l(t, \tau)$ : length of fatigue crack in the concrete under protrusions of reinforcement at time $t$.

During the cyclic loading and under the great stress influence of concrete smashing under the reinforcement protrusions, the deformations of cyclic stress-induced creep develop rapidly. Since the number of loading cycles $N$, due to the cyclic stress-induced creep of concrete reinforcement, under the protrusions of reinforcement that surrounds them, is an increase in the movement growth $g_{0}^{\max }(t)$ on the loaded end and inside the fastening $g_{x}^{\max }(t)$, which, in turn, leads to the redistribution of catenation forces $P_{i, r}$ from the more loaded protrusions at the end of the fixing to the protrusions located at the bottom of the fixation. This means that there is a redistribution 
of the catenation stress $\tau_{g}$ by the length of fastening. In this case, an increase in the number of loading cycles leads to a continuous increase in the length of the plastic section and to the increase of the completeness of the clutch's circuit of stresses.

In elements with a large distance from the element's support to the location of the concentrated force action $\left(a_{0} / h_{0}>2\right)$ (Figure 4), the objective exhaustive strength of an inclined compressed strip at a brief moment of time $t$ is defined by an analogy (4):

$$
\begin{aligned}
& f_{c d, \text { rep }}(t)=\frac{\left(k_{s c f}(t)+K_{l s w}(t)\right) \cdot l(t) \cos \gamma \operatorname{ctg} \varphi}{x_{p l} \sqrt{\pi l(t)} \cdot Y(l)} \times \\
& \times\left\langle 1-\left[\frac{G_{c} L_{\varepsilon}}{\sin ^{2} \varphi}+\frac{6 E_{s} I_{s} L_{\varepsilon} \cdot n \cdot \cos (\varphi-\gamma) \sin \gamma}{\left(d_{s} \cdot \sqrt[4]{\frac{E_{s}}{E_{c}}} \cdot\left(1,4+1,25 \sqrt[4]{\frac{a_{s}}{d_{s}}}\right)\right)^{3} \sin \varphi}\right] \times\right. \\
& \left.\left.\times\left\{\frac{1}{E_{c}}+C_{e} \prod_{k=1}^{k=n} K_{k} a \psi_{v}+\int_{t_{o}}^{t} H_{\sigma} \frac{\partial}{\partial \tau}\left[\frac{1}{E_{c}(\tau)}+\right] d t\right\}\right\rangle^{-1}+C(t, \tau)\right]
\end{aligned}
$$

where $l(t), Y(l), k_{s c f}, L_{\varepsilon}, G_{c}, E_{s}, I_{s}, n, d_{s}, E_{c}, a_{s}, C, C_{e}, K_{k}, a, \psi v, \varphi$ are according to (4).

$K_{1 s w}$ is according to (6).

$x_{p l}$ : height of plastic zone.

$\gamma$ : inclination angle of straight line segment that models end part of danger inclined crack, $\gamma=\operatorname{arctg} V_{c 1}^{\max } / N_{c 1}^{\max }$.

$H_{\sigma}$ : function of stress accumulations, for concrete $H_{\sigma_{c}}=1+\sigma_{1}^{a d d}(t) / \sigma_{1 c}^{\max }\left(t_{0}\right)$, for reinforcement $H_{\sigma_{s}}=1+\frac{E_{s} \cdot A_{s} \cdot L_{\varepsilon} \cdot H_{\varepsilon}}{b \cdot l_{s} \cdot \omega_{s} \cdot \sin ^{2} \varphi}, \quad$ for transverse reinforcement $H_{\sigma_{w}}=1+\frac{0,5 \cdot E_{s} \cdot m \cdot A_{s w} \cdot L_{\varepsilon} \cdot H_{\varepsilon}}{b \cdot l_{s w} \cdot \varpi_{s w} \cdot \cos a \times \sin ^{2} \varphi}$, $\omega_{s}, \omega_{s w}$ : stress distribution completeness coefficients, respectively, in longitudinal and transverse reinforcement, in the first approximation $\omega_{s}=\omega_{s w}=0,8$.

The limit of endurance (objective strength) $f_{s d, b}(t)$ of the longitudinal reinforcement at time $t$ in the place of its intersection with the critical inclined crack under plane stress conditions is determined by (7) and (8). The endurance limit (objective strength) of the anchoring longitudinal reinforcement $f_{y d, \text { an }}(t)$ on the critical inclined crack is determined by (6). The endurance limit under axial load $f_{y d w, \text { rep }}(t)$ is determined by (7) and (8) by considering that $\tau_{s w}^{\max }=0$. 


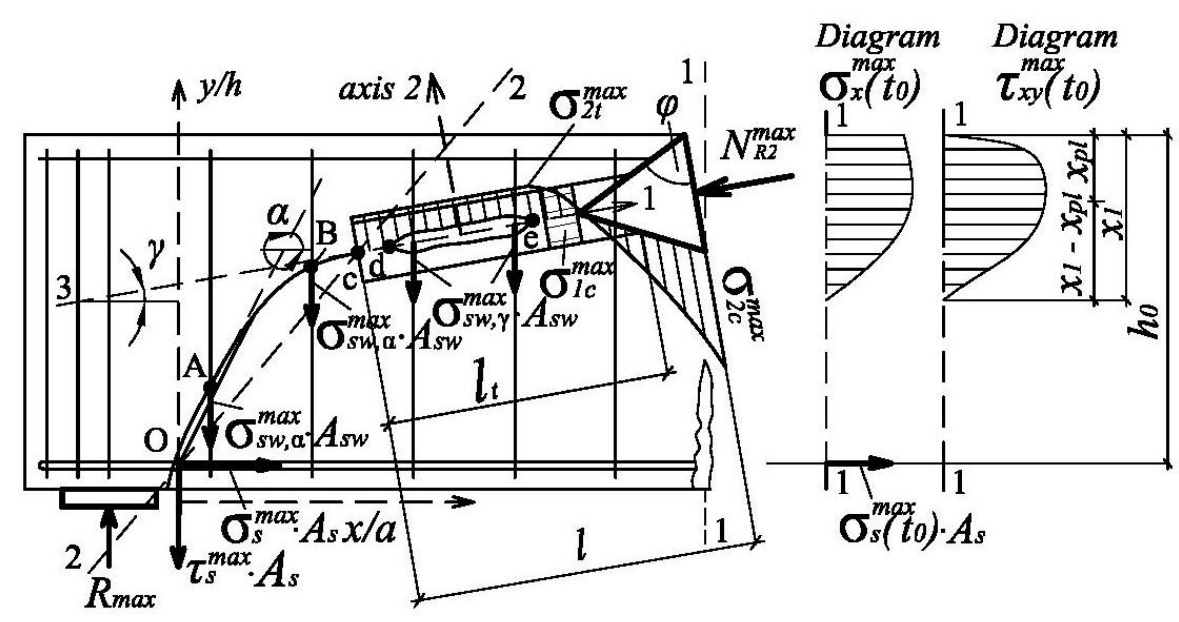

Figure 4 Physical and analytical models of fatigue resistance for area near the support of the reinforced concrete element with a large distance from element's support to location of concentrated force action

where $\varphi, \sigma_{1 c}^{\max }(t)$ are according to Figure 1.

$h_{0}=d$ is according to Figure 2.

$l, l, R_{\max }, \sigma_{2 t}^{\max }(t), \sigma_{2 c}^{\max }(t)$ are according to Figure 3.

$x_{p l}$ : length of plastic zone.

$\gamma$ : inclination angle of straight line segment that models end part of danger inclined crack, $\gamma=\operatorname{arctg} V_{c 1}^{\max } / N_{c 1}^{\max }$.

$\tau_{s w}^{\max }, \sigma_{s w}^{\max }:$ maximum tangential and normal stresses of transverse reinforcement bars.

$\tau_{s}^{\max }, \sigma_{s}^{\max }$ : maximum tangential and normal stresses of longitudinal reinforcement bars.

$N_{R 2}^{\max }$ : force in compressed zone within plastic area.

$A_{s w}$ : cross-sectional area of transverse reinforcement bars.

Tests [2] of the rectangular section reinforced concrete elements with the distance from the element's support to the location of the concentrated force action $a_{0}=c_{0}=(1,51-1,67) h_{0}$ revealed the formation and development of cracks and the nature of the exhausting destruction in the area of the transverse forces and bending moments, as shown in Figure 5. By the middle distance from the element's support to the location of the concentrated force action, the fatigue occurs with the formation of a critical inclined crack. However, the destruction also affects the local stress state disturbance and the stress concentration in these areas. The critical inclined crack may form in the distance $(0,2 \ldots 0,3) h$ on the stretched verge and grow in the directions of the support and concentrated external force. In the stretched zone, it develops along lines 2-2 (Figure 5), which connects the inside edges of the support plate to the outer face of the loading plate and completely crosses the area near the support (to the inside edges of the supporting plate).

With development from the support to the concentrated force, the direction of the critical inclined crack changes after it approaches point 0 , i.e., the intersection of lines 2-2 and 3-3, and continues to develop along line 3-3 on the axis of the inclined compressed strip. Moreover, inside the compressed force flux through the line of the tensile stress action, $\sigma_{2 t}^{\max }$ is formed and develops a crack separation $d-e$ along the 3-3 axis. Then, it merges with the original plot $\mathrm{OO}_{2}$ of the critical crack. Obviously, the creation, development, and disclosure of critical cracks in the tensile zone (area $\mathrm{OO}_{2}$ ) are connected to the rotation and shearing action of the inclined section 2-2, while its development and disclosure in the compressed area $(\mathrm{ed})$ are caused by the formation and development of section 
micro-cracks behind the tensile stress line of the action (Figure 5) in the area of "tension-compression" within the inclined compressed force flux formed by the force $P_{\beta}^{\max }$. Then, they are merged into a macro-crack with a further development and opening of macro-crack separation. The distribution of stresses inside the inclined compressed force flux is the same as that in the elements shown in Figure 3.

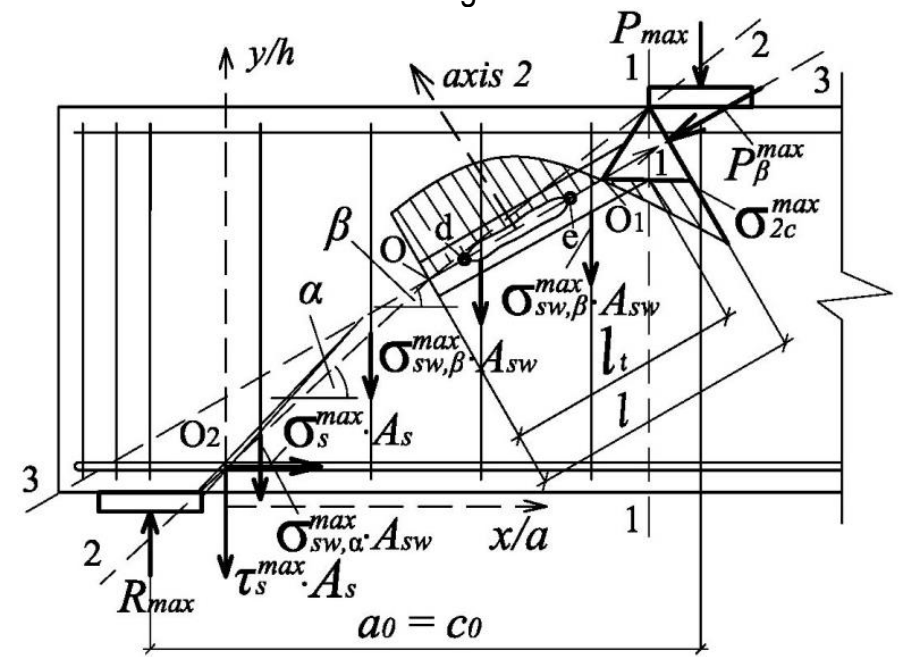

Figure 5 Physical and analytical models of reinforced concrete element fatigue resistance with medium distance from element's support to location of concentrated force action

where $P_{\max }, \varphi, \sigma_{1 c}^{\max }(t)$ are according to Figure 1 .

$h_{0}=d$ are according to Figure 2 .

$l_{t}, l, R_{\max }, \sigma_{2 t}^{\max }(t), \sigma_{2 c}^{\max }(t)$ are according to Figure 3.

$\tau_{s w}^{\max }, \sigma_{s w}^{\max } ; \tau_{s}^{\max }, \sigma_{s}^{\max } ; A_{s w}$ are according to Figure 4.

$P_{\beta}^{\max }$ : objective (residual) strength of inclined compressed strip.

$\beta$ : inclination angle of straight line segment that models the end part of the danger inclined crack, $\beta=\operatorname{arctg} \frac{h_{0}}{c_{0}}$

For this case of the stress-deformation state and fracturing nature, the objective fatigue strength (endurance limit) of the inclined compressed strip of the concrete over the critically inclined crack takes the following form:

$$
f_{c d, \text { rep }}(t)=\frac{\left[k_{s c f}(t)+K_{1 s w}(t)\right] l(t) \operatorname{ctg} \varphi}{l_{\text {sup }} \sin \beta \sqrt{\pi l(t)} Y(l)} \times\left(\begin{array}{l}
1-\left\{\frac{G_{c} L_{\varepsilon}}{\sin ^{2} \varphi}+\frac{6 E_{s} I_{s} L_{\varepsilon} n \cdot \cos (\varphi-\beta) \sin \beta}{\left[d_{s} \sqrt[4]{\frac{E_{s}}{E_{c}}\left(1,4+1,25 \sqrt[4]{\frac{a_{s}}{d_{s}}}\right)}\right]^{3}} \sin \varphi\right] \times \\
\times\left\{\frac{1}{E_{c}}+C_{e} \prod_{k=1}^{k=n} K_{k} a \psi_{v}+\int_{t_{0}}^{t} \frac{\partial}{\partial \tau}\left[\frac{1}{E_{c}(\tau)}+C(t, \tau)\right] d t\right\}
\end{array}\right)
$$

The endurance limits of the transverse and longitudinal reinforcement and the endurance limits of their anchoring are determined according to (7), (8), and (9).

The presented theoretical data were compared to experimental data obtained by previous studies [10, 11]. The character of deformation, cracking, and destruction of specimens, completely confirmed the considered 
physical models and the possibility of using the proposed calculation apparatus. The divergence between the calculated and experimental values of destructive shear loading was considered in the method for calculating the strength of the investigated element sections that was developed. This method will be considered further in future work.

\section{CONCLUSION}

In this study, the basics of fracture mechanics in the areas near the supports of the reinforced concrete bending elements under cyclic loading action were investigated. Four exhausting destruction physical models of structures were considered depending on the change of distance from support to the location of center-point loading. It was established that the change of this factor affects the destruction scheme and the distribution of existing forces in the force flux of concrete and the reinforcement of an element.

On this basis, the expression for the determination of the endurance limit (fatigue strength) for concrete in the compressed inclined strip, the longitudinal reinforcement in the place of its intersection with the inclined crack, and the endurance limit of the longitudinal reinforcement anchoring were proposed.

Moreover, the influence of cyclic strain-induced creep deformations and the accumulation of damages in the form of fatigue cracks were taken into account under cyclic loading conditions.

By using the proposed calculation device, a designer will be able to estimate the objective (residual) strength inclined sections of the bending reinforced concrete structures under cyclic loading action.

\section{References}

[1] SBN B.2.6-98: 2009 Concrete and Reinforced Concrete Structures. The Main Provisions, Standard of Ukraine, Kyiv.

[2] Mirsayapov, I. 2009: Endurance of Reinforced Concrete Structures under the Action of Shear Forces: Abstract of ScD Thesis: Specialty 05.23.01 - «Building Constructions, Buildings and Structures», Kazan.

[3] Babich, E.; Gomon, P.; Filipchuk, S. 2012: Work and Calculation of the Bearing Capacity of Bending Tsections Reinforced Concrete Elements under the Influence of Repeated Loads, Edition of NUWNM, Rovno.

[4] Zinchuk, N. 2008: Strength and Deformability of Reinforced Concrete Bending Elements under Low-Cycle Loadings in Conditions of Elevated Temperatures: Abstract of PhD Thesis: Specialty 05.23 .01 - «Building Constructions, Buildings and Structures», Lviv, Ukraine.

[5] Melnik, S.;Borisjuk, O.;Kononchuk, O.;Petrishin, V. 2008: The Research of Reinforced Concrete Beams Work under the Action of Low-Cycle Loading, Economical Resource Materials, Constructions, Buildings and Structures, 17 (1), pp. 404-410. (in Ukrainian)

[6] Kovalchik, J.; Koval, P. 2014: Investigation of Crack Resistance of Prestressed Reinforced Concrete Beams under the Influence of Low-Cycle Loading, Scientific and Practical Aspects of the Automobile and Transport Industries of the Road, 45 (1), pp. 282-287. (in Ukrainian)

[7] Babich, V. 2003: Features of Continuous Reinforced Concrete Beams Work under the Repeated Loads, Building Constructions, 58 (1), pp. 8-13. (in Ukrainian)

[8] Drobyshinec, S.;Babich, E. 2004: Work of Fiber Concrete and Fiber Reinforced Concrete Beams under the Action of Monotonic and Repeated Loadings, Composite Structures. Research, Design, Construction, Operation, 6 (1), pp 65-71. (in Ukrainian)

[9] Valovoj, M. 2008: The Strength, Crack Resistance and Deformability of Concrete Beams under the Influence of Repeated Loads, Composite Structures. Research, Design, Construction, Operation,8 (1), pp. 45-48. (in Ukrainian)

[10] Karpiuk, V.; Albu, K.; Danilenko, D.; Somina Yu. 2014: Experimental Investigations of Reinforced Concrete Beams Performance under the Influence of Cyclic Loading, Papers and Commentaries of the 2 nd International

Karpiuk, V, Kostiuk, A, Maistrenko, O, Somina, Y 
Academic Congress "Fundamental and Applied Studies in America, Europe, Asia and Africa", 2 (1), pp. 682696.

[11] Dorofeev, V.; Karpiuk, V.; Albu, K; Somina, Yu. 2016: Strength and Crack Resistance of Reinforced Concrete Beam Structures under the Action of Low-Cycle Loads of Constant Sign and Cyclic Alternating Loadings of High Levels, Bridges and Tunnels. Theory, Research, Practice, 10 (1), pp. 13-26. (in Ukrainian)

[12] Kornejchuk, A.; Masjuk, G. 2008: Experimental Study of Bearing Capacity of Inclined Cross Sections of Bending Reinforced Concrete Elements under the Action of Low-Cycle Alternating Loads, Economical Resource Materials, Constructions, Buildings and Structures, 16 (2), pp. 217-222. (in Ukrainian)

[13] Zalesov, O.; Klimov Y. 1989: Strength of Reinforced Concrete Structures under the Action of Transverse Forces, Builder, Kyiv.

[14] Zalesov, O. 1993: Calculation of bending elements for endurance, taking into account the analytical diagrams of deformation of concrete and reinforcement, Concrete and Reinforced Concrete, 4(1), pp. 22-24. (in Ukrainian)

[15] Kholmyanskiy, M. 1997: Concrete and Reinforced Concrete: Deformability and Strength, Building Edition, Moscow.

[16] Sokolov, B.1992: A New Approach to Calculating the Strength of Concrete Elements under Local Load Action, Concrete and Reinforced Concrete,10 (1), pp. 22-24. (in Ukrainian)

[17] Baranova, T.; Zalesov, A. 2003: Frame-Rod Calculating Models and Engineering Calculating Methods of Reinforced Concrete Structures, Association of Construction Universities Edition, Moscow.

[18] Goto, I. 1971: Cracks Formed in Concrete Around Deformed Tension Bars, ACl Journal, 68 (4), pp. 244-251.

[19] Karpenko, N. 1996: General Models of Reinforced Concrete Mechanics, Building Edition, Moscow.

Please cite this article as:

Karpiuk, V, Kostiuk, A, Maistrenko, O, Somina, Y: Influence of intermittent cyclic loading on reinforced concrete resistance model, Electronic Journal of the Faculty of Civil Engineering Osijek-e-GFOS, 15, pp.59-74, https://doi.org/10.13167/2017.15.6 